\title{
Contra la genuflexión y el cipayismo académico en materia de ciencia, investigación y publicación
}

\section{Un análisis de la hora}

\author{
Andrés Mombrú Ruggiero \\ amombru56@gmail.com \\ Rec. 09/06/2018, Apr. 14/07/2018
}

En momentos en que en nuestro país el sistema de ciencia y técnica está siendo desmembrado -como Tupac Amaruc en la Plaza de Armas de Cuzco-, resulta difícil

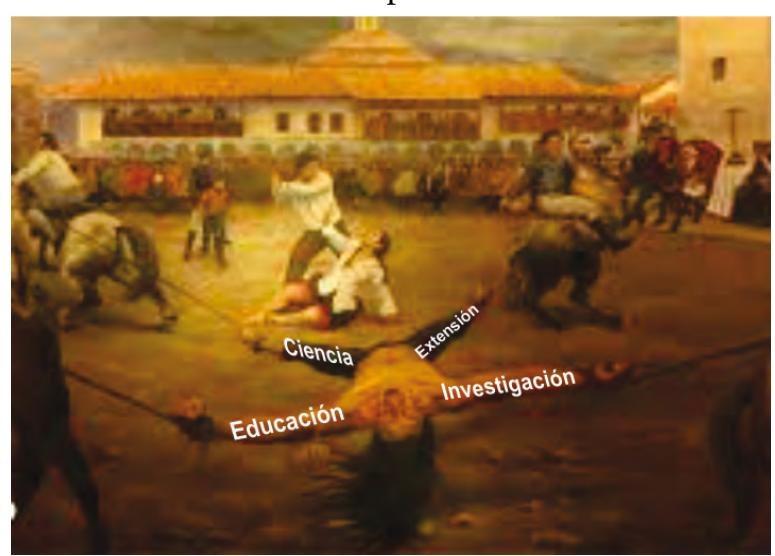
realizar cualquier tipo de evaluación o diagnóstico sobre las virtudes y defectos del estado de la investigación en Argentina. Pero, es bueno recordar que en nuestro país se alternaron períodos de apoyo a la investigación científica y a la educación, con décadas en las que tanto la educación como la investigación y la extensión, -los tres pilares de las universidades públicas argentinas- se vieron vapuleados por gobiernos de turno que no solamente desfinanciaron todas las áreas de la cultura, sino que destruyeron lo poco o mucho que se había hecho y arruinaron proyectos, labores y emprendimientos que, además de perjudicar a los investigadores, devastaron el desarrollo científico y humano del país, impidiendo algo imprescindible para un bien fin, que es la continuidad.

La llamada fuga de cerebros, que es más difícil de reponer que los millones de dólares que se han fugado en divisas, implica un retroceso tal, que no se soluciona con inversiones económicas que se pudieran realizar ni a corto ni a mediano plazo. El panorama inmediato es un retrotraimiento de la capacidad de producción de conocimiento y por lo tanto, el retorno a un estado de colonización en materia de ciencia y técnica. El problema ya no será la

1 Dr. Andrés Mombrú Ruggiero UNLa/UBA. 
compra en el extranjero de los insumos para la realización de investigaciones, sino la importación de resultados bajo la forma de patentes multimillonarias. El modelo agroexportador no solamente desindustrializa al país y arroja a la miseria a cientos de miles de trabajadores, atenta contra la autonomía y la soberanía en materia de producción de conocimiento.

Las políticas actuales en ciencia y técnica son incapaces de favorecer investigaciones que permitan, siquiera, el desarrollo, y por lo tanto, la mayor rentabilidad del proyecto agroexportador que el gobierno impulsa. Se trata de una política que adolece de la capacidad de distinguir en la ciencia aquello que le puede llegar a beneficiara. Es, sin duda, una política implementada por la brutalidad, la ignorancia y la incompetencia, de quienes no sólo no entienden que es la ciencia, sino en que mundo viven. Si no son capaces de comprender la importancia para su propio beneficio del INTA (Instituto Nacional de Tecnología Agropecuaria) -al que están descuartizando-, menos lo serán para entender la de otros organismos de investigación vinculados a la industria, a las ciencias exactas, a las ciencias sociales y menos todavía de la humanidades y las artes. Cómplices de Monsanto y Bayer, sus rentas extraordinarias prefieren compartirlas con las multinacionales de la alimentación que con la ciencia argentina y condenan así su propio futuro, ya que las tecnologías agropecuarias de esas multinacionales no son sustentables a largo plazo, generando la desertificación y la pérdida de las especies nativas. Se podrá decir, que para cuando el daño esté realizado, la cantidad de dinero que habrán acumulado les permitirá sustraerse de cualquier preocupación económica, pero, iiel dinero no se come!!! Por este camino, nos enfrentamos a consecuencias tan terribles como las que anticipaba el film de 1973 "Cuando el destino nos alcance" del director Richard Fleischer, una distopía en la que comer frutas, verdura o carne era un lujo, y casi toda la población se alimentaba de galletas hechas con los desechos de la superpoblación humana. ${ }^{2}$ Porque estas políticas no afectan sólo a nuestro país sino que se dan a nivel global; y allí no estará la investigación científica para tratar de poner remedio a una irracionalidad predatoria que afectará a todos, sin distinción de color, creencia o clase. Sólo una política regional para la investigación en ciencia y técnica puede permitir conocer los riesgos y adoptar medidas ecológicamente sustentables.

Pero no nos engañemos, los científicos no son víctimas propiciatorias que se sacrifican en nombre del bien común y la "verdad" y se encuentran a merced de las corporaciones y los Estados; por el contrario, la comunidad científica también está estratificada institucionalmente entre: a) quienes investigan lo que establece que hay que investigar lo que definen las políticas de investigación, b) los que no se someten y son expulsados del campo y c) los que lisa y llanamente son cómplices del poder manipulador del conocimiento por parte de organismos estatales o de corporaciones multinacionales.

La ciencia, lamentablemente, no es democrática, es jerárquica y verticalista en su organización. Sin embargo, puede asumir una actitud crítica frente a los proyectos políticos que la determinan y financian. Para ello, es imperioso que erradiquen de su seno la idea de que su hacer es "valorativamente neutro" e "ideológicamente aséptico" y que reconozca que se encuentra atravesada por los mismos modelos ideológicos, políticos y económicos que el resto de la sociedad. A todas las pugnas dentro de la comunidad científica: de intereses, de egos; a las luchas por el reconocimiento, por el prestigio $y$, en definitiva, por el poder que deviene de ellos, se deben sumar otros factores; las de- 
mandas políticas y sociales que exigen determinados resultados con fines prácticos. Esos fines pueden deberse a intereses corporativos o colectivos, por ello, siempre dependerá del proyecto político en el que se encuentre inmersa la investigación científica, lo que determinará las líneas de investigación que las impulse.

En definitiva, la promoción de la ciencia depende del orden político, ya se trate de los gobiernos, los ministerios, las agencias u otras instituciones gubernamentales. No se trata de promover una ciencia embanderada con partidos políticos, ni tener la ingenuidad de que se pueda sustraer de la política, sino pensar en qué orden político y económico la ciencia puede ejercer la producción de conocimiento con un sentido integral.

¿Cómo reconocer el rumbo que las ciencias toman y el modo en que afrontan los distintos compromisos y presiones que las atraviesan?

En sintonía con diferentes políticas científicas fueron apareciendo, a partir de la década del setenta en el mundo, y de los noventa en Argentina, los organismos de evaluación, con un principio rector a la cabeza, los indicadores de I\&D (Investigación más Desarrollo). Todos ellos basados en modelos anglosajones. Estos organismos evalúan, de acuerdo a indicadores preestablecidos, el desempeño de universidades, institutos, centros y concejos de investigación y otorgan reconocimientos, certificaciones o dejan fuera del sistema, según sus criterios. El quedar excluido significa la desfinanciación y, por lo tanto, la imposibilidad de obtener las condiciones mínimas para llevar adelante proyectos de investigación. El dinero no es infinito y se hace necesario neutralizar a los oportunistas que se aprovechan de financiaciones en el campo para sobrevivir de los sistemas de subsidios, becas y otras instancias de reparto de dinero. Si los criterios de evaluación, acreditación y financiación fueran en ese sentido, la discusión podría darse en torno a la relevancia o no de ciertos proyectos, pero el caso es que bajo la figura de la irrelevancia, no se neutraliza a los oportunistas, sino que se suelen destruir proyectos de interés social, comunitario, regional, para el beneficio de intereses privados que no solamente privilegian a algunos, sino que perjudican existencialmente a muchos, como muy claramente se puede ver en el área de la salud, de la soberanía alimentaria, o de las formas productivas, entre otros.

El epistemólogo argentino, Mario Bunge, fue sindicado como cientificista y con razón, ya que se empecinó en reafirmar su exitosa distinción entre ciencia básica, ciencia aplicada y tecnología. Se revela en su postura la incapacidad de ver como las políticas científicas han conducido a un tecno-mercantilismo que reduce a la actividad científica a una práctica instrumentalista. Sin embargo, Bunge ha sido lo suficientemente lúcido como para ver intereses espurios detrás de la relaciones político tecnológicas, pero no ha tenido esa lucidez para visualizar la complicidad de lo que él denomina ciencia básica y ciencia aplicada, con la política que las financia, tal como si la pureza de la ciencia fuera el resultado de la probidad de los científicos, de la libertad de investigación y no del entramado del sistema de ciencia y técnica con las entidades financiadoras. No quiso admitir que esa situación es promovida por las políticas de ciencia y técnica que se someten a los modelos de cientificidad, que provienen de los organismos financieros internacionales y que dejan con muy pocas chances a la llamada libertad científica. En su afán de pensar a una ciencia desvinculada de la política, olvidó que no hay ciencia sin política, pues la ciencia no surge del interés intelectual de los hombres, ni de la cu- 
riosidad por conocer, sino de los proyectos políticos que las sociedades construyen para llevar adelante algún tipo de realización signada siempre por una concepción ideológica. Lo seres humanos no buscan por naturaleza el beneficio personal en detrimento de la comunidad; esa actitud, o la inversa, o cualquier otra posible, son el resultado de una construcción político social. Los valores de una sociedad no bajan de un cielo del bien, sino que se construyen en los conflictos que los animan.

Quienes afirman que la ciencia se ha convertido en tecno-ciencia, al servicio de una razón técnico instrumental, no se equivocan, pero no todas lo hacen desde el mismo lugar, ni se deben evaluar del mimo modo. Se pueden distinguir voces críticas de ese tecno-cientificismo, pero puede haber diferencias muy sustantivas en esas críticas:

Algunos realizan sus críticas desde la vieja herencia del misticismo religioso, que rechazó el heliocentrismo y la teoría de la evolución, en ellos prevalece el fideísmo y atacan a la ciencia desde un misticismo radical. Otros la cuestionan desde el pensamiento crítico en el campo de la filosofía y de la epistemología, pero abarcan un espectro tan amplio como el que va de los frankfurtianos a los postestructuralistas y los posmodernos.

No es poco común ver alianzas circunstanciales entre los fideístas y los críticos, cuando de criticar las teorías y las prácticas científicas se trata. Allí vuelve a primar el precepto de que el enemigo de mi enemigo es mi amigo.

Un tercer grupo realiza una apología lisa y llana de la tecno-ciencia; son aquellos que se encuentran comprometidos con los usos y fines instrumentales de la investigación científica. A su vez, estos pueden dividirse entre los que piensan en la ciencia como formas de mejorar las ganancias y los que la piensan como la forma de mejorar condiciones sociales. En ambos casos olvidan que todo fin instrumental termina siendo cosificador y deshumanizante; así se haga en nombre de los poderes económicos concentrados o en nombre del pueblo.

Las políticas estatales de I\&D son determinantes en la financiación de las investigaciones -del mismo modo que la pauta publicitaria para las empresas periodísticas- y una sociedad que no sea capaz de diseñar estrategias para atender a las necesidades sociales, no impulsará una política científica que atienda al desarrollo local.

En Argentina se ha invertido un promedio del 0,6\% del PBI, en los últimos años, siete veces menos que Israel que ha invertido el 4.3\% (UNESCO, 2015). El gobierno anterior pretendía llevarlo al 1\% para el Bicenternario, pero no se llegó, a pesar de ello revitalizó el sistema de ciencia y técnica como nunca antes se había hecho. Piénsese también que se habla en términos relativos al PBI, que había crecido entre 2003 y 2015 un promedio de $5 \%$ anual, con picos de $9,2 \%$ en 2005 y $0,1 \%$ en 2009 , ańo de la crisis mundial. (Ministerio de Hacienda, 2018)

¿Con un presupuesto de "déficit cero" que se propone el gobierno para este año, con un recorte de aproximadamente 500 mil millones de pesos, principalmente en las áreas de salud, educación, ciencia y técnica, que expectativas quedan para el desarrollo de una ciencia autónoma y de una investigación enfocada en los problemas regionales? 
Está claro que las políticas neoliberales, de países como el nuestro, no tienen los mismos estándares y las mismas aplicaciones que en los países centrales, sean grandes o pequeños. El neoliberalismo que se aplica en Argentina es también un neocolonialismo. La transferencia de riquezas de los sectores bajos y medios de la sociedad a los sectores concentrados de la economía, son un peldaño de la transferencia de la riqueza del conjunto del país a la corporación financiera internacional. Los neoliberales del primer mundo también apuntan a reformas laborales, impositivas, eliminación de subsidios, recorte del empleo público, privatización de empresas, pero, sus inversiones en I\&D siguen teniendo altos porcentajes de su PBI, más de 7 veces en algunos casos -como se ha señalado en párrafos anteriores- y en educación, países como Dinamarca, Islandia, Corea del sur, Israel, Estados Unidos, han invertido en los últimos años entre el 7\% y el 8\% de su PBI. Desde 2006, Argentina incrementó del 4,7 \% al $6 \%$ en 2010 y fluctuó entre ese guarismo y el $6,5 \%$ hasta $2016 .{ }^{3}$ Con el recorte muy sustantivo programado, una devaluación de más del $50 \%$ en los últimos meses y una inflación que se prevée con un piso de un $45 \%$, los indicadores de educación caerán estrepitosamente.

Sin embargo, nuestra miseria actual y la que se proyecta para el futuro inmediato y más lejano, no comienza ahora. No nos referimos a episodios del pasado, como, a modo de ejemplo: La noche de los bastones largos, que marcó una época oscura de la universidad y de la ciencia argentina, sino los modos en que la ciencia argentina prosperó, bajo modelos reproductores de esquemas que no convergían con los modelos emancipadores que se suponía propiciaban. En este sentido, las políticas científicas de nuestro país no difirieron con los modelos de otros países y de ese modo se han sometido a un criterio universalizado de ciencia de carácter cientificista. No alcanza con poner más dinero para investigación y educación, es necesario implementar políticas científicas con sustento epistemológico que sean afines a proyectos emancipadores.

Como decíamos al principio, es muy difícil realizar algún tipo de diagnóstico sobre el estado actual de la investigación en Argentina, debido al desfinanciamiento y desmantelamiento de las instituciones de investigación; pero como se dice comúnmente, "no hay mal que dure cien años" y si durase ya no importaría. En igual situación se encuentra la educación, de la que depende la formación de los científicos que están siendo preparados para el futuro. De los cinco premios Nobel argentinos, tres fueron científicos, y dos, de la paz; lo que indica que la tenacidad puede resistir los embates de la brutalidad, pero no puede haber desarrollo genuino de la investigación científica sin continuidad y sin políticas científicas que le den sustento, no solo en los programas y proyectos de investigación, sino en la educación que es la instancia formadora.

Pero no todas las ciencias han sido tratadas del mismo modo. En este sentido, las ciencias abstractas, pueden ser, quizás, menos vejadas, por un lado porque los sensores suelen tener pocos manejos de esos temas, por otro, porque nunca se sabe que desarrollo matemático puede solucionar problemas balísticos, o que aplicación lógica pueda ser aplicada a la inteligencia artificial. El caso de las ciencias naturales o experimentales es el más emblemático, ya que, si bien sus investigaciones pueden resultar poco vinculadas con lo inmediato, ejemplo de ello 
es la astronomía; de ciencias como la física, la química y la biología, derivan, todo el tiempo, innovaciones que permiten la elaboración de nuevos productos para el mercado.

Las ciencias sociales han resultado, y resultan, más conflictivas, pues buena parte del pensamiento crítico se ha refugiado en ellas durante muchas décadas, pero las finalidades instrumentalistas aumentan todo el tiempo, impulsadas por estrechos y estrictos criterios metodológicos que las convierten cada vez más en herramientas recolectoras de datos que pueden ser utilizados con cualquier finalidad. Hoy, a las ciencias sociales, parece importarles cada vez más obtener datos que pensar los problemas sociales.

Volviendo entonces al tema de la evaluación; el cuantitativismo de los modelos de evaluación, bajo la modalidad $\mathrm{I} \& \mathrm{D}$, supedita los resultados de las investigaciones a los réditos que pudiera producir en materia de desarrollo. Las metas suelen ser el desarrollo económico, sustentado bajo el desarrollo productivo y este, a su vez, bajo el desarrollo tecnológico. En esos términos se aprecia tanto la investigación en ciencias naturales, cuanto en ciencias sociales, y también en ciencias formales, independientemente de los proyectos políticos que los impulsan. Como se ha visto, para los neoliberales vernáculos, tener una ciencia propia es "vivir por encima de nuestras posibilidades", por lo tanto, para ellos conviene comprar los productos que las ciencias de otros países permiten producir, cambiándolos por soja. Para los proyectos progresistas en cambio, -colocando bajo este amplio manto gobiernos democráticos interesados en una ciencia centrada en la atención de los problemas locales- desde hace poco más de un siglo a esta parte independientemente de la ideología del gobierno, se ha pensado a la ciencia como un hacer neutro, que alcanza con establecer políticas de ciencia y técnica y darles la financiación suficiente como para que resulten en emprendimientos provechosos para el país. Pero, ¿qué hay de las instancias que regulan concretamente la actividad de producción de conocimiento científico, más allá de las diferencias filosóficas y que, en definitiva, pueden producir beneficios similares a los que se producen en los países centrales, pero también muchos de los males que de ellos se derivan? ¿Qué hemos hecho por cambiar las formas de producción, reproducción e intercambio científico en relación con proyectos que se pretenden emancipadores?

El sistema meritocrático que se produjo a partir de las evaluaciones científica en el contexto de I\&D, generó formas y criterios de evaluación que miden el impacto de las producciones científicas a través de papers. Como se sabe, el impacto, no mide calidad, sino cantidad de citaciones. Al mismo tiempo, el sistema de evaluación por pares, que abre o cierra las puertas a las publicaciones más selectas, se convierte en un círculo cerrado, en el cual siempre hay algunos más pares que otros. Quien quiera ver una conexión directa entre los artículos aprobados, el negocio de las revistas científicas y las líneas de investigación impuestas por las instituciones científicas, no se equivoca; pero a su vez, lo que las instituciones científicas establecen, proviene de lo que los "fondos de inversión" solicitan. De ese modo, esas políticas establecen la dirección y los recursos que se asignarán a las investigaciones, dejando el tema de la libertad científica, de la autonomía para la investigación, en mera retórica. Se han llevado adelante también, otras formas de evaluación, con criterios econométricos y bibliométricos, que, además de la evaluación por pares, pretenden medir: impacto a través de sistema de citas, publicaciones, etc. 
La producción de un grupo de investigación se expresa en su cantidad de publicaciones. La productividad se expresa como el número de publicaciones por equivalentes persona-año en las investigaciones. (Rousseau: 1998)

Es decir, muchas publicaciones dan buen puntaje, pocas publicaciones poco, independientemente de la calidad o de los efectos de esas investigaciones sobre la vida de sus congéneres. Supuestamente, estos indicadores tienen el respaldo de las publicaciones prestigiosas en las que han salido los "papers" y de la revisión por pares. Otro artículo demandaría dar cuenta de la enorme cantidad de fraudes y otros delitos perpetrados a través de revistas científicas del más alto nivel.

El creciente reporte de las conductas aquí descritas, aunado a otras conductas "más conocidas" como las mencionadas al inicio de este escrito, ${ }^{4}$ representan grandes retos para quienes participamos y defendemos la publicación científica, como la condición sine qua non para determinar la contribución de la investigación a la generación de nuevo conocimiento. En este sentido, la responsabilidad de velar por mantener la honestidad y las buenas prácticas en el proceso de la publicación científica, no solo debe recaer en los autores, editores y revisores de las revistas, sino también en las entidades (públicas y privadas) que realizan mediciones de producción científica, en los docentes y formadores de nuevos investigadores y hasta en los mismos lectores. (Díaz: 2006)

Las declaraciones, como la que se cita, de Gloria Mercedes Díaz, más allá de sus buenas intenciones -que pueden resultar inocuas o incluso servir para mostrar que hay un poco de crítica, incluido lo que expresamos aquí-, pone sobre el tapete formas de actuar dentro de ese ámbito -que la sociedad en general tiene por integro- y que es el de la ciencia, donde se cometen todo tipo de delitos. Pero debe quedar claro, que lo más grave no es la deshonestidad intelectual de los involucrados en sentido personal, sino el obrar corporativo que entrega a la investigación científica en las manos de los que sólo ven en ella lucro y poder.

Juan Miguel Campanario (2009), profesor de la Universidad de Alcalá, da cuenta de 19 casos de ganadores del premio Nobel que antes de haberlo obtenido habían sufrido el rechazo de sus teorías por parte de la comunidad científica y de 24 investigadores por cuyos trabajos recibieron ese premio, que fueran rechazados por los editores de prestigiosas revistas científicas. El statu quo científico es el peor enemigo del desarrollo de una ciencia al estar comprometida con los intereses corporativos y la industria de la producción de conocimiento. Estas son algunas de las consecuencias del accionar institucional sometido a una razón dogmatizada y a la difusión científica como negocio.

Randy Schekman, premio Nobel de Medicina 2013 por sus estudios sobre biología celular, se ha manifestado en reiteradas oportunidades como crítico de las revistas científicas -a las que él llama de lujo- porque son nocivas para un saludable desarrollo de la ciencia. El diario El País de España, publicó en diciembre de 2013 un artículo de su autoría titulado: "Por qué revistas como 'Nature', 'Science' y 'Cell' hacen daño a la ciencia” y allí señala:

4 Se refiere a todo tipo de delito en el ámbito de las publicaciones académicas. El artículo denuncia fraudes, cobros indebidos, plagios, falsos factores de impacto, falsos evaluadores, violación de autrorías, etc. 
Estas revistas promocionan de forma agresiva sus marcas, de una manera que conduce más a la venta de suscripciones que a fomentar las investigaciones más importantes. Al igual que los diseñadores de moda que crean bolsos o trajes de edición limitada, saben que la escasez hace que aumente la demanda, de modo que restringen artificialmente el número de artículos que aceptan. Luego, estas marcas exclusivas se comercializan empleando un ardid llamado "factor de impacto", una puntuación otorgada a cada revista que mide el número de veces que los trabajos de investigación posteriores citan sus artículos. La teoría es que los mejores artículos se citan con más frecuencia, de modo que las mejores publicaciones obtienen las puntuaciones más altas. [...]

Es habitual, y muchas revistas lo fomentan, que una investigación sea juzgada atendiendo al factor de impacto de la revista que la publica. Pero como la puntuación de la publicación es una media, dice poco de la calidad de cualquier investigación concreta. Además, las citas están relacionadas con la calidad a veces, pero no siempre. Un artículo puede ser muy citado porque es un buen trabajo científico, o bien porque es llamativo, provocador o erróneo. Los directores de las revistas de lujo lo saben, así que aceptan artículos que tendrán mucha repercusión porque estudian temas atractivos o hacen afirmaciones que cuestionan ideas establecidas. Esto influye en los trabajos que realizan los científicos. (Schekman, 2013)

Los profesores universitarios suelen quejarse porque los estudiantes "no saben leer", "no saben escribir", "no hay lectura comprensiva", y es un muy mal indicador del estado de nuestra educación primaria y secundaria. Esto es, sólo en parte, la causa de la deserción y el fracaso de los estudiantes universitarios, que según la mayoría de los estudios, ronda el $70 \%$, o sea, que de cada 10 estudiantes, sólo se titulan 3. No nos interesa aquí dar cifras comparativas, ya que el tema que estamos tratando no es la deserción universitaria, sino la calidad de la producción de conocimiento que genera la investigación.

En un artículo, publicado en esta revista por el autor de este mismo artículo (Mombrú 2017), se hace referencia a las encrucijadas que atraviesa el educador de las universidades públicas argentinas, que se encuentra enmarcado en la figura de docente-investigador y que lo enfrenta a una actividades para las que no cuenta con la formación adecuada, ya que pocos docentes universitarios son profesores con formación pedagógica y muchos menos han atravesado instancias de formación para la investigación.

La mayoría de los investigadores, se han hecho investigadores investigando, no recibiendo una formación académica para tal fin, y a pesar de ello, hay algunos que llegan a ser muy buenos, pero la mayoría no. Y es que la escolarización universitaria sigue respondiendo a esquemas pedagógicos en los que se capacita para responder sobre textos leídos, pero no a producir textos, pues en escasas oportunidades los propios docentes llegan a manejar la escritura académica. Esto se advierte en la escasa producción propia de libros de los docentes universitarios -nos referimos a titulares- que, al conjunto de fotocopias de otros autores en la bibliografía, raramente suman materiales de su propia 
factura. Este es un tema de educación superior muy complejo que merece una consideración aparte, pero es justamente allí, en la exteriorización de la producción por medio de publicaciones donde se advierte la vacancia de una capacidad imprescindible para que la investigación alcance sus mejores frutos, a la hora de comunicar, de enseñar, de producir y de publicar.

Ese uso público de la razón, que como señalaba Kant en "¿Qué es la ilustración?" (2005 [1784]) permite ejercer la condición de "Docto", mediante publicaciones, es el indicador más claro de nuestra miseria actual. Son ahora los editores de revistas científicas los que hablan. Los investigadores "no saben escribir", "no saben comunicar por escrito", "no saben atenerse a normas de publicación" y podríamos agregar, "tienen poca idea de que es investigar". Por supuesto que no nos referimos al tipo de ignorancia que presentan los estudiantes que provienen del secundario, pero hay enormes desbalances en la formación académica, e incluso en los posgrados y en los sistemas de evaluación, que son la causa de nuestra condición de subdesarrollo científico. Ya no podemos echarle la culpa a la escuela primaria y a la secundaria, aunque se requiere una reestructuración radical de esos niveles de estudio si se quisieran mejores resultados. Tampoco separando en la formación universitaria la formación profesional de la formación científica. Ese divorcio podría traer consecuencias peores que las que intenta solucionar, ya que los profesionales deben estar consustanciados con los más altos estándares científicos y los científicos no deben perder sentido de la realidad separándose de la práctica profesional.

Es imperioso que el número de revistas científicas aumente en cantidad y en calidad, no porque ponga al país a nivel de las publicaciones más prestigiosas y "nos ponga en el mundo". Ya que ese mundo, produce un tipo de ciencia, y lo vincula de tal modo con las necesidades sociales, que sólo puede traer para nosotros mayor miseria; sino porque son las publicaciones las que nos permiten socializar, compartir, interactuar, exteriorizar nuestras producciones y creaciones en las prácticas reales de la interdisciplinariedad. Pero para ello se requiere emanciparse del vasallaje de los patrones internacionales en materia de evaluación, acreditación y validación.

¿Qué pasaría, si en lugar de evaluar a las revistas en base a criterios de citación, se hiciera en función de criterios de incidencia transformara de las sociedades en las que se sitúan? ¿Qué pasaría si la calidad de una revista se considerara en función de su capacidad de intercambio y compenetración con el territorio? ¿Qué pasaría si el reconocimiento no viniera de la industria cultural de las revistas científicas, ni del mercado de los catalogadores, sino de otro tipo de indicadores, tales como la incidencia de los artículos de investigación que se publican en cuanto producen aportes específicos al desarrollo del área disciplinar? ¿Qué pasaría si los criterios de evaluación tuvieran en cuenta que distintos tipos de revistas tienen distintos tipos de propósitos y que se plantean distintos objetivos?

¿Para qué futuro educamos?, se preguntaba hace algunas décadas la pedagoga uruguaya Reina Reyes. Parafraseando esa interrogante podríamos preguntarnos, ¿para qué futuro investigamos?, ¿para qué futuro publicamos?, ¿para qué proyectos individuales y colectivos trabajamos? Difícilmente estas preguntas encuentren una respuesta que nos rescate a nosotros mismos, si no somos capaces de "salir de nuestra autoculpable minoría de edad", pensando por cuenta propia, y fundamentalmente mientras no abandonemos el colonia- 
lismo cultural en el que nos vemos sometidos cuando agachamos la cabeza y aceptamos de modo incondicional los parámetros que evalúan las condiciones de investigación y publicación impuestos por los mercaderes de la ciencia. Construyamos nuestras propias redes y reflexionemos juntos sobre los temas de nuestro común interés y determinemos un modo de evaluarnos que al criterio de "impacto" contraponga la socialización del conocimiento.

\section{Bibliografía}

- Campanario, J. M. (2009). "Rejecting and resisting Nobel class discoveries: accounts by Nobel Laureates". Scientometrics, 81(2), pp.549-565.

— Díaz, G. M. (2016). "El fraude en las publicaciones científicas: más allá de fabricar, falsificar y plagiar”. Tecno Lógicas, 19(36).

— Galiani, S. (2017). "Recursos del sistema educativo y su performance en Argentina". Foco Económico, un blog latinamericano de economía y política. Disponible en http://focoeconomico.org/2017/03/12/recursos-del-sistema-educativo-y-su-performance-en-argentina/

— Kant, I. (2005 [1784]). “Qué es la ilustración?”. En Ensayos sobre la paz, el progreso y el ideal cosmopolita (pp. 21-31). Madrid: Cátedra.

- Ministerio de Hacienda, Presidencia de la Nación. (2018). "Informe de avance del nivel de actividad primer trimestre de 2018”. En Informes Técnicos, 2(9), 2018. Recuperado de https://www.indec.gob.ar/uploads/informesdeprensa/pib_06_18. pdf

— Mombrú Ruggiero, A. (2017). "Propiedad, apropiación y robo en torno a la autoría”. Perspectivas Metodológicas, 2(21), pp. 45-54.

- Rousseau, R. (2001). "Indicadores bibliométricos y econométricos en la evaluación de innstituciones ciecntíficas". Acimed, (9), pp. 50-60.

- Schekman, R. (2013). "Por qué ravistas como 'Nature', 'Science' y 'Cell' hacen daño a la ciencia". En El País, (sección sociedad). Recuperado de https://elpais. com/sociedad/2013/12/11/actualidad/1386798478_265291.html

— UNESCO (2018). "Informe de la UNESCO sobre la Ciencia”. Recuperado de: https://es.unesco.org/unesco_science_report/figures 